\title{
Endoscopic treatment of staple line disruption in patient with vertical banded gastroplasty using the over-the-scope-clip system (with video)
}

\author{
Fedoua Rouibaa", M. Surace, Marc Barthet
}

Department of Gastroenterology, Hôpital Nord, Marseille, France

Email: "rouibaa@yahoo.fr

Received 20 June 2012; revised 20 July 2012; accepted 31 July 2012

\begin{abstract}
Background: scope-clip (OTSC; Ovesco Endoscopy GmbH, Tuebingen, Germany) system is a newly designed method for the mechanical compression of large areas in the gastrointestinal tract. So far, indications for OTSC application are hemostasis of primary or post-interventional bleeding, closure of iatrogenic full thickness or covered perforations. Recently clo- sure of gastrointestinal tract fistulas using this device has been described. Objective: In this case, we de- scribe the successful endoscopic closure, using the OTSC system, of a gastrogastric fistula due to staple line disruption in patient with vertical banded gas- troplasty. Conclusion: Endoscopic application of the OTSC device is safe and effective for the treatment of a staple line disruption.
\end{abstract}

Keywords: Bariatric Surgery; Mason’s Gastroplasty; Staple Line Disruption; Clips OVESCO

\section{INTRODUCTION}

Morbid obesity and its related comorbidities is a worldwide epidemic. Surgery is, in contrast to conventional treatment modalities, the only treatment with a proven long-lasting effect on weight and comorbidities and has a positive effect on the quality of life .Vertical banded gastroplasty (VBG), also known as stomach stapling, is a restrictive surgery for weight control in extreme obesity. It was described in 1982 by Mason [1]. Both a band and staples are used to create a small stomach pouch with restrictive effect. It was the most popular technic during the 90's in Europe. Although VBG have been shown to be effective in achieving weight loss in the first few years without metabolic side-effects, Weight loss more than 5 years after VBG varies in the literature from $30 \%$ to $59 \%$ [2]. The long-term results of O'Brien et al. show that, 10 years

\footnotetext{
*Conflict of interest disclosure: no.
}

"Corresponding author. after gastric banding, it is still successful, and weight loss is comparable with gastric bypass (59\% and 52\% respectively) [3].

The late failure of VBG due to staple line disruption, pouch dilation, and change of eating habits to "sweet eaters" cause body weight regain in about $20 \%$ of patients [3]. Leakage of vertical staple line is the main complications of VBG. It occurs in 27 to $48 \%$ [4], usually justifying reintervention. A surgical reintervention was usually proposed but new endoscopic treatments were developed to reduce postoperative morbidity. Several endoscopic methods have been described: covered self expendable stents, endoscopic clipping or suturing, electrical and chemical cauterization of the fistula and fibrin glue sealant [5-7]. Recently, a new system of clips (OTSC, OVESCO Endoscopy GmbH, Tuebingen, Germany) was developed. In our paper, we describe the successful endoscopic closure, using the OTSC system, of a gastrogastric fistula due to staple line disruption in patient with vertical banded gastroplasty, without postprocedure complications.

\section{CASE PRESENTATION}

We report the case of a 46-year-old woman who underwent bariatric surgery type Mason in 2001 for morbid obesity with Body Mass Index (BMI) of $41 \mathrm{~kg} / \mathrm{m} 2$. The short term outcome was perfectly spectacular as her BMI decreased to 21 after one year. The long term outcome, after 10 years, was characterized by a weight regain and increase of her BMI to 41. The upper endoscopy performed in April 2011, found two larges fistulas on the staple line of $15 \mathrm{~mm}$ and $20 \mathrm{~mm}$ (Figure 1); with normal pouch. An endoscopic over-the-scope clip (OTSC, Figure 2) was applied on each fistulas. These two clips permitted the complete closure of the fistulas without post-procedure complication (Figure 3, video: "Figures 4 (a)-(c)") thus avoiding surgery. The short and midterm results was favorable without post-procedure complications. 


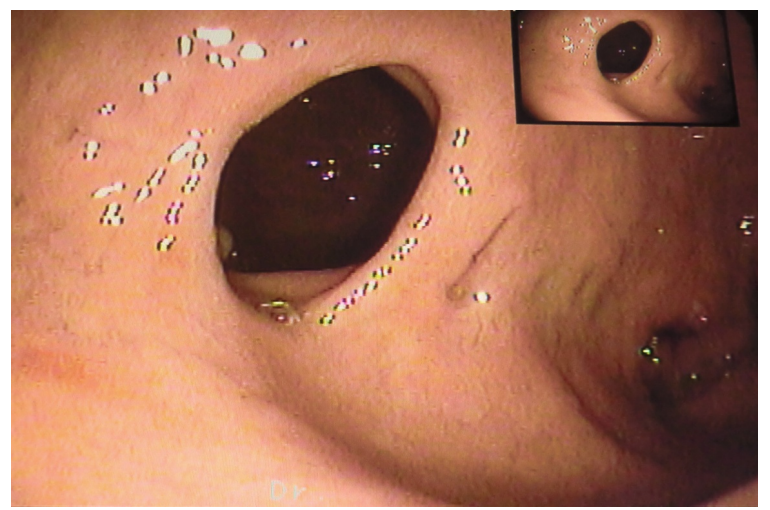

Figure 1. Endoscopic view of the gastro-gastric fistula.

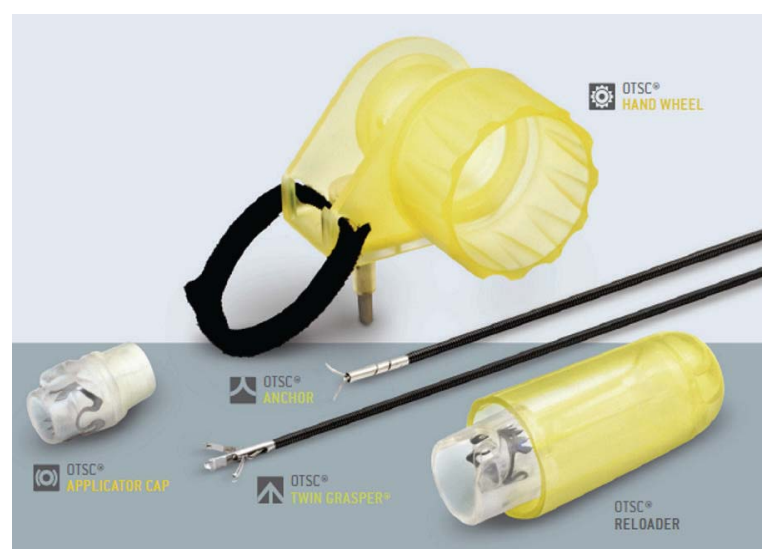

Figure 2. The OTSC system.

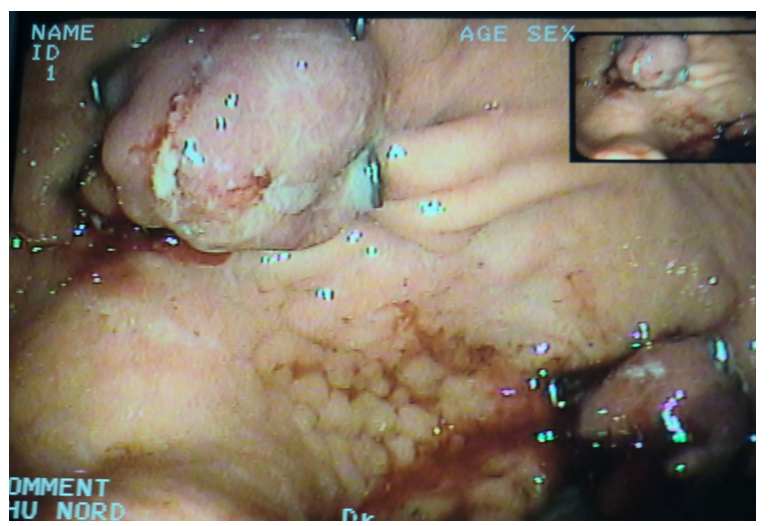

Figure 3. Endoscopic view of the closure of gastro-gastric fistulas by two OTSC clips.

\section{DISCUSSION}

Vertical banded gastroplasty (VBG) is associated with a number of early and late complications that can increase morbidity and mortality, and result in re-operation or revision surgery [4]. Early complications are: acute gastric dilatation, leak and peritonitis. Late complications include: staple line disruption, pouch dilation and change of eating habits to "sweet eaters" that can cause body weight regain in about $20 \%$ of patients [4].

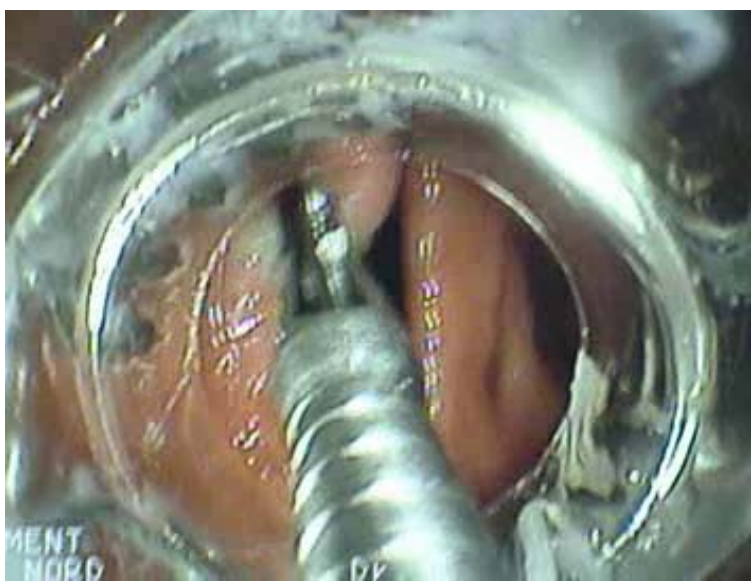

(a)

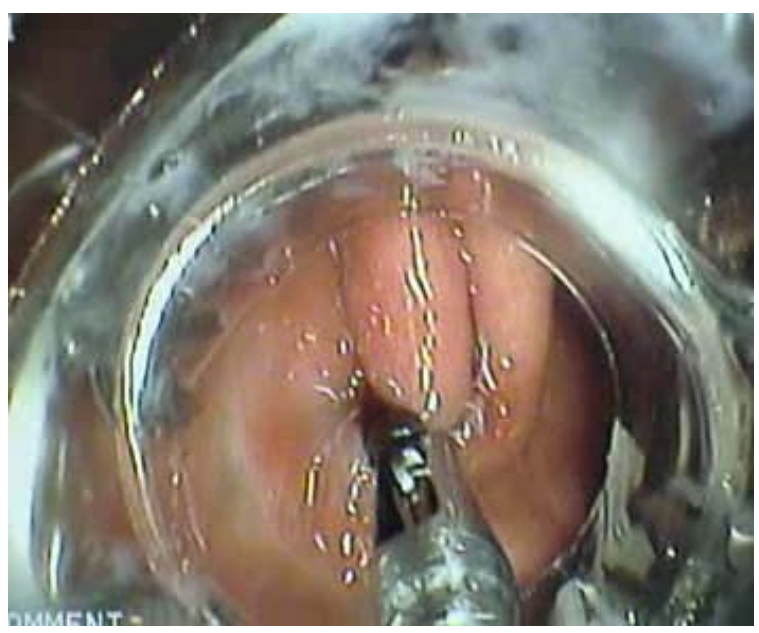

(b)

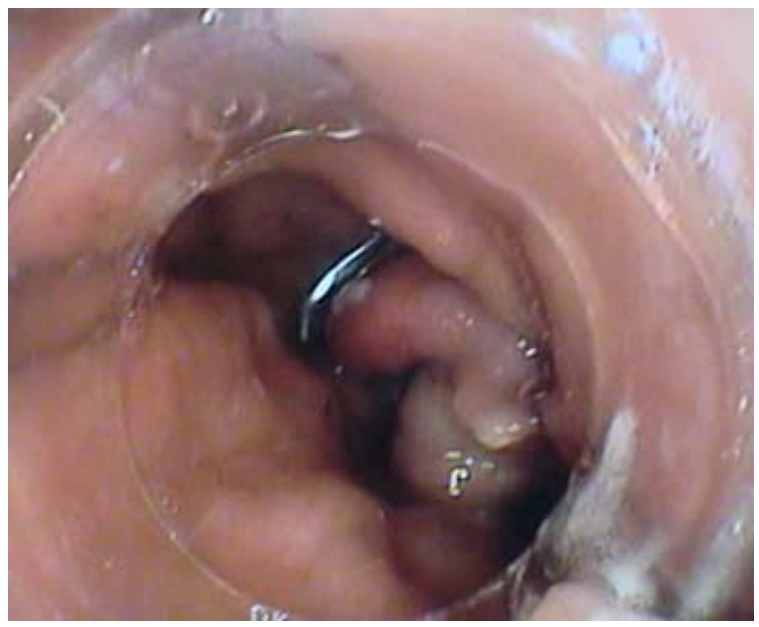

(c)

Figure 4. (a), (b), (c): the gastric orifice of the gastrocutaneous fistula during endoscopic application of the OTSC device.

Staple-line disruption and anastomotic leaks are devastating complications of VBG with high morbidity and mortality in the acute setting, and chronically may lead to fistula formations, such as gastrogastric fistulas that 
lead to weight regain. Given the high morbidity and mortality associated with the operative management of staple-line complications, alternative endoscopic approaches have been explored. Endoscopic treatment of some bariatric complications is feasible and efficient. Covered stents are one method that has been developed as a means of primary endoscopic closure. In a meta-analysis of seven studies involving 77 subjects, in whom self-expanding stents were utilized for management of postbariatric surgery leaks, the pooled proportion of successful leak closure was $84.5 \%$ [8]. Other means of primary closure have also been reported. Multiple case series demonstrated the feasibility of utilizing a variety of endoscopic techniques, such as fibrin glue, hemoclips, endoscopic suturing devices, sclerotherapy, Surgisis (an acellular matrix biomaterial derived from the porcine small intestine submucosa that stimulates proliferation of fibroblasts), and argon plasma coagulation for the repair of chronic fistula resulting from anastomotic leaks or in combination with covered self-expandable metallic stents for refractory fistulas cases [7,9-12].

The over-the-scope-clip (OTSC) system (Ovesco Endoscopy GmbH, Tuebingen, Germany) is a newly designed method that has recently been used in the closure of gastrointestinal tract fistulas. So far, indications for OTSC application are hemostasis of primary or postinterventional bleeding, closure of iatrogenic full-thickness or covered perforations [13]. In our case, this device has been used successfully for the closure of two larges gastrogastric fistulas due to staple line disruption in a patient with VBG. This technique has also been described in others indications: chronic gastrocutaneous fistulas, revisional endoscopy of dilated pouch-outlet after gastric bypass $[13,14]$. The short and midterm results in these indications were favorable. Although the OTSC-technique appears feasible and promising, long-term data about their efficacy and durability are lacking.

\section{CONCLUSION}

Our case adds to the previous literature demonstrating the role of OTSC clip in the closure of staple-line disruption and anastomotic leaks after bariatric surgery. The OTSC application is a safe and effective endoscopic method for the treatment of gastrointestinal fistulas, but prospective comparative studies are needed to work out the sufficiency and efficacy of this new method.

\section{REFERENCES}

[1] Mason, E.E. (1982) Vertical banded gastroplasty for obesity. Archives of Surgery, 117, 701-706. doi:10.1001/archsurg.1982.01380290147026
[2] Balsiger, B.M. et al. (2000) Ten and more years after vertical banded gastroplasty as primary operation for morbid obesity. Journal of Gastrointestinal Surgery, 4, 598-605. doi:10.1016/S1091-255X(00)80108-0

[3] O’Brien, P.E. et al. (2006) Systematic review of medium-term weight loss after bariatric operations. Obesity Surgery, 16, 1032-1040.

doi:10.1381/096089206778026316

[4] Edward, E.M. and Joseph, J.C. (2003) Management of complications in vertical banded gastroplasty. Current Surgery, 60, 33-37. doi:10.1016/S0149-7944(03)00042-4

[5] MacLean, L.D., Roche, B.M., Sampalis, J. and Force, R.A. (1993) Results of surgical treatment of obesity. The American Journal of Surgery, 165, 155-160. doi:10.1016/S0002-9610(05)80420-9

[6] Puli, S.R., Spofford, I.S. and Thompson, C.C. (2010) Use of self expanding stents in the treatment of bariatric surgery leaks: A meta-analysis and systematic review. Gastrointestinal Endoscopy, 71, AB140. doi:10.1016/j.gie.2010.03.134

[7] Eskaros, S., Ghevariya, V., Krishnaiah, M., Asarian, A. and Anand, S. (2009) Percutaneous endoscopic suturing: An effective treatment for gastrocutaneous fistula. Gastrointestinal Endoscopy, 70, 768-771. doi:10.1016/j.gie.2009.05.002

[8] Papavramidis, T.S., Kotzampassi, K., Kotidis, E., Eleftheriadis, E.E. and Papavramidis, S.T. (2008) Endoscopic fibrin sealing of gastrocutaneous fistulas after sleeve gastrectomy and biliopancreatic diversion with duodenal switch. Journal of Gastroenterology and Hepatology, 23, 1802-1805. doi:10.1111/j.1440-1746.2008.05545.x

[9] Merrifield, B.F., Lautz D. and Thompson, C.C. (2006) Endoscopic repair of gastric leaks after Roux-en-Y gastric bypass: A less invasive approach. Gastrointestinal Endoscopy, 63, 710-714. doi:10.1016/j.gie.2005.11.018

[10] Hammed, H., Kalim, S. and Khan, Y.I. (2009) Closure of a nonhealing gastrocutaneous fistula using argon plasma coagulation and endoscopic hemoclips. Canadian Journal of Gastroenterology, 23, 217-219.

[11] Fernandez-Esparrach, G., Lautz, D.B. and Thompson, C.C. (2010) Endoscopic repair of gastrogastric fistula after Rouxen-Y gastric bypass: A lessinvasive approach. Surgery for Obesity and Related Diseases, 6, 282-288. doi:10.1016/j.soard.2010.02.036

[12] Toussaint, E., Eisendrath, P., Kwan, V., Dugardeyn, S., Deviere, J. and Le Moine, O. (2009) Endoscopic treatment of postoperative enterocutaneous fistulas after bariatric surgery with the use of a fistula plug: Report of five cases. Endoscopy, 41, 560-563.

doi:10.1055/s-0029-1214606

[13] Iacopini, F., di Lorenzo, N., Altorio, F., Schurr M.O. and Scozzarro, A. (2010) Over-the-scope clip closure of two chronic fistulas after gastric band penetration. World Journal of Gastroenterology, 16, 1665-1669. doi:10.3748/wjg.v16.i13.1665

[14] Kouklakis, G., Zezos, P., Liratzopoulos, N., Gatopoulou, A., Oikonomou, A., Pitiakoudis, M., Efremidou, E. and 
Simopoulos, C. (2011) Endoscopic treatment of a gastrocutaneous fistula using the over-the-scope-clip system: A
Case Report. Diagnostic and Therapeutic Endoscopy, 2011, 5 Pages, Article ID: 384143. 